\title{
IDENTIFYING BUFFER SIZE IN FRONT OF CAPACITY-CONSTRAINED RESOURCE WITH PARALLEL PROCESSES
}

\author{
Zinovy Radovilsky, California State University, East Bay, Hayward, California, USA \\ Micah Frankel, California State University, East Bay, Hayward, California, USA
}

dx.doi.org/10.18374/IJBR-13-4.18

\begin{abstract}
In this paper, we provide a new modeling approach of identifying the optimal buffer size in front of a capacity constrained resource (CCR) with parallel processes. The time buffer is a critical element of the drum-buffer-rope method in the Theory of Constraints (TOC), and it is used to protect CCR from inevitable disruptions in production and service processes, and to provide maximum CCR's productivity. The model is formulated in terms of a finite multi-server queue. The new modeling approach is based on calculating the optimal number of units waiting in line (the optimal buffer size) in front of a multi-server CCR in order to maintain the highest net profit of the CCR's throughput while protecting the constrained resource from becoming idle. A numeric example and analysis of this new modeling approach proves it efficiency in terms of maximizing the throughput profitability of a multi-server CCR with parallel processes, and reducing a chance of this constrained resource to become empty.
\end{abstract}

Keywords: Time Buffer, The Theory of Constraints (TOC), Drum-Buffer-Rope (DBR), finite multi-server queue, optimization. 